\title{
Origens e distribuições das artérias mesentéricas cranial e caudal em fetos de javalis (Sus scrofa scrofa, Linnaeus -1758)
}

\author{
Andréa Regina Abrantes Gomes ${ }^{1 *}$ \\ Frederico Ozanam Carneiro e Silva ${ }^{2}$ \\ Lucas de Assis Ribeiro ${ }^{1}$ \\ Tharlianne Alici Martins de Souza ${ }^{1}$ \\ Universidade Federal de Uberlândia \\ ${ }^{1}$ PPG em Ciências Veterinárias \\ ${ }^{2}$ Departamento de Anatomia Comparativa, Faculdade de Medicina Veterinária \\ * Autor para correspondência \\ Rua David Canabarro, 1380, apto 201, CEP 38402-032, Uberlândia - MG, Brasil \\ andreagomes85@gmail.com
}

Submetido em 07/07/2012

Aceito para publicação em 07/01/2013

\section{Resumo}

Estudou-se o comportamento anatômico das artérias mesentéricas cranial e caudal em 21 fetos de javalis, fêmeas e machos, nos quais foi injetada, através da aorta torácica, solução de Neoprene Látex “450”, corada com pigmento específico e, em seguida, eles foram fixados em solução de formol a 10\%. A análise dos resultados permitiu afirmar que a artéria mesentérica cranial originou-se da aorta abdominal, caudalmente à artéria celíaca, emitiu ramos adrenais direito e esquerdo, pancreáticos, e as artérias pancreático-duodenal caudal, jejunais, cólicas média e direita, e ileocecocólica. A artéria mesentérica caudal surgiu da aorta abdominal, de seu terço caudal, e emitiu as artérias cólica esquerda e retal cranial. Foram verificadas anastomoses entre artérias jejunais, cólica esquerda e retal cranial, e cólicas esquerda e média. Nas três espécies, as artérias mesentéricas cranial e caudal, pancreático-duodenal caudal, jejunais, cólicas direita e média, e ileocecocólica apresentaram padrões vasculares semelhantes, visto que as diferenças quanto a emissão de ramos ou surgimento isolado ou em tronco comum não alteraram o suprimento sanguíneo.

Palavras-chave: Anatomia comparada; Aparelho digestório; Irrigação; Suidae

\section{Abstract}

Origins and distributions of the cranial and caudal mesenteric arteries in fetuses of wild boars (Sus scrofa scrofa, Linnaeus - 1758). The anatomical behavior of the cranial and caudal mesenteric arteries was studied in 21 wild boars fetuses, female and male, in which one injected, through the thoracic aorta, a Neoprene Latex " 450 " solution, stained with a specific pigment and, then, they were fixed in a $10 \%$ formaldehyde solution. The analysis of results allowed one to state that the cranial mesenteric artery originated from the abdominal aorta, caudal to the celiac artery, issuing right and left adrenal branches, pancreatic, and the caudal pancreaticduodenal, jejunal, middle and right colic, and ileo-ceco-colic arteries. The caudal mesenteric artery originated from the abdominal aorta, from its caudal third, issuing the left colic and the cranial rectal arteries. Anastomoses were found between jejunal, left colic and cranial rectal, and left and middle colic arteries. In the three species, 
the cranial and caudal mesenteric, caudal pancreatic-duodenal, jejunal, right and middle colic, and ileo-cecocolic arteries showed similar vascular patterns, whereas the differences with regard to emission of branches or isolated emergence or emergence in common trunk didn't change the blood supply.

Key words: Comparative anatomy; Digestive apparatus; Irrigation; Suidae

\section{Introdução}

A origem do javali (Sus scrofa scrofa) remonta a milênios, sendo este o ancestral do porco doméstico, o qual resultou através de cruzamentos em um animal completamente diferente daquele que o originou (LUI et al., 2006). A ocorrência de híbridos entre javalis e suínos, tanto na natureza quanto em cativeiro, é bastante comum, uma vez que o cruzamento entre essas subespécies gera indivíduos férteis (SEABRIGHT, 1972). Esse fato levou certos criadores a praticarem este tipo de acasalamento como forma de aumentar os índices zootécnicos, explorando um possível efeito heterótico e consequente melhoria na lucratividade do setor (ANDERSSON et al., 1998).

Quando comparada à carne bovina, a carne do javali apresenta $85 \%$ menos calorias, $31 \%$ mais proteínas, $15 \%$ mais minerais, cinco vezes menos gorduras e um índice de colesterol tangendo a zero, porém, decorrente das dificuldades de aquisição de exemplares para criação e seu baixo ganho de peso quando comparados a outras espécies, torna sua exploração comercial pouco atraente (LUI et al., 2006).

No que concerne o padrão vascular da artéria mesentérica cranial, Getty (1981), Schwarze e Schröder (1991) e Silva et al. (1998), em suínos, e Machado et al. (1999), em queixada, afirmaram que esta é oriunda da face ventral da aorta abdominal, em posição caudal à artéria celíaca. Schwarze e Schröder (1991) e Silva et al. (1997) mencionaram a presença de ramos pancreáticos provenientes da artéria mesentérica cranial em suínos.

A artéria pancreaticoduodenal caudal é citada por Getty (1981) e Nickel et al. (1981) referindo-se aos suínos, como sendo o primeiro ramo emitido pelas artérias mesentérica cranial.

No tocante às artérias jejunais, Schwarze e Schröder (1991) evidenciam a variação em número de 10 a 12, ao passo que, Getty (1981) relata a presença de
42 a 79 destas, tanto diretas como indiretas. Silva et al. (1997; 1998; 1999; 2000) relatam a ocorrência de grande número de anastomoses dos ramos das artérias jejunais.

A artéria cólica direita surgiu da artéria mesentérica cranial em tronco comum com artéria cólica média. Em relação à artéria cólica média, vale ressaltar os relatos de que tal vaso anastomosa-se com a artéria cólica esquerda, ramos da mesentérica caudal (CALÁBRIA; SILVA, 2005; SCHWARZE; SCHRÖDER, 1991).

Referente à artéria ileocecocólica, esta é proveniente da face esquerda da artéria mesentérica cranial e se dividi em ileocecal e ramo cólico, sendo que a primeira bifurca-se em artéria cecal e ileal. (GETTY, 1981; SILVA et al., 1999; CARVALHO et al., 2002; DYCE, et al., 2010). Todavia, Nickel et al. (1981) utilizam o termo artéria ileocólica, a qual origina os ramos cólico e ileomesentérico e a artéria cecal.

Ao tratarem da origem e ramificações da artéria mesentérica caudal, os autores supracitados afirmam que tal vaso origina-se da face ventral da aorta descendente abdominal, próximo à sua terminação em correspondência à última vértebra lombar, sendo sempre ímpar e emitindo, após um curto trajeto, as artérias cólica esquerda e retal cranial.

Considerando a necessidade do acréscimo de dados anatômicos comparativos entre suínos domésticos e os javalis, objetivou-se estudar as origens e distribuições das artérias mesentéricas de javalis.

\section{Material e Métodos}

Foram utilizados 21 fetos de javalis natimortos, fêmeas e machos, procedentes de doações do IBAMA e do LAPAS (Laboratório de pesquisas com animais silvestres) da Universidade Federal de Uberlândia.

Os exemplares inicialmente foram mantidos congelados até o inicio das dissecações. O preparo 
destes iniciou-se pela incisão da parede torácica, ao longo do nono espaço intercostal esquerdo. Realizou-se a canulação da aorta abdominal, injetando, no sentido caudal, solução de Neoprene Látex “450”, corada com pigmento específico. Em seguida, os animais foram imersos em solução aquosa de formol a $10 \%$, onde permaneceram por período mínimo de $72 \mathrm{~h}$, para iniciar as dissecações das artérias mesentéricas cranial e caudal.

A documentação dos resultados foi realizada a partir de desenhos esquemáticos e fotografias das origens e distribuições das artérias mesentéricas cranial e caudal. A nomenclatura adotada para descrição dos resultados esteve de acordo com o Nomina Anatômica Veterinária (INTERNATIONAL COMMITTEE ON VETERINARY GROSS ANATOMICAL NOMENCLATURE, 2005).

Foi evidenciado o comportamento anatômico destas, na sua frequência, bem como suas ramificações e distribuições. Os dados foram expressos por fotos, sendo a análise estatística foi do tipo descritiva através de porcentagem simples.

\section{Resultados}

No presente estudo, verificou-se que a artéria mesentérica cranial, em todos os fetos, surgiu isoladamente da face ventral da aorta abdominal, em posição caudal à artéria celíaca (Figuras 1, 2,3).

Ramos adrenais direitos foram observados em 15 exemplares $(71,4 \%)$, sendo que era único em 13 casos $(87 \%)$ e duplo nos outros dois $(13 \%)$.

Ramos adrenais esquerdos estavam presentes em nove animais examinados $(42,8 \%)$, sendo um ramo em três casos $(33,3 \%)$ e dois em seis exemplares $(66,7 \%)$.

Foram observados troncos comuns de ramos hepáticos e para a parede da veia cava caudal e hepatogástrico em um exemplar $(4,7 \%)$.

Ramos pancreáticos, visualizados em 15 casos $(71,4 \%)$, variaram em número de dois a quatro ramos (Figura 3).
FIGURA 1: Origem da artéria mesentérica cranial (Mcr), caudalmente à artéria celíaca $(\mathrm{Ce})$, na face ventral da artéria aorta abdominal $(\mathrm{Ab})$.

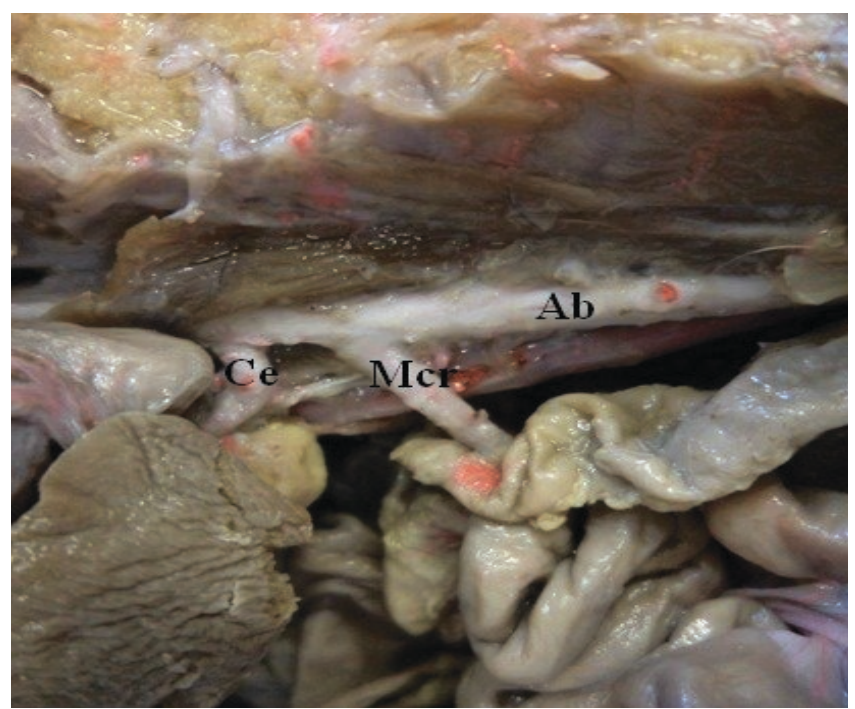

FIGURA 2: Vista lateral esquerda da cavidade abdominal do javali. Pode-se visualizar a artéria mesentérica cranial (Mcr) dando origem ao tronco comum das artérias cólicas média (Colm) e direita (Cold), artérias jejunais(J), artéria ileocecocólica (Icco).

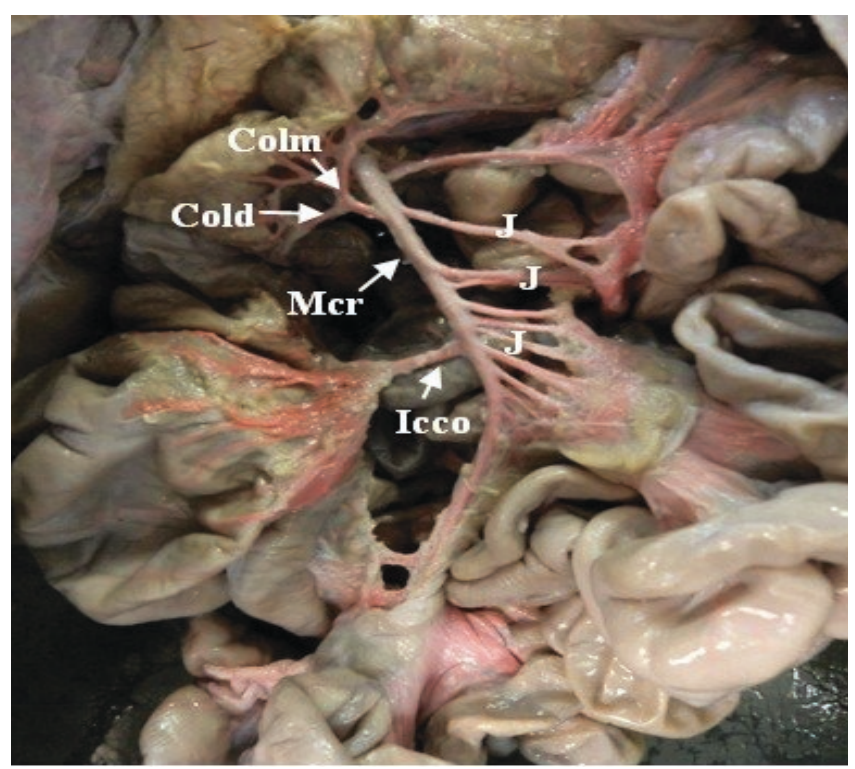

Artéria pancreáticoduodenal caudal, presente em todos os animais analisados, originou-se isoladamente da borda caudal da artéria mesentérica cranial de um ponto proximal em relação à primeira artéria jejunal, sendo que em oito casos (38\%) emitiram três ramos, em seis espécimes $(28,5 \%)$ quatro, em quatro animais 
(19\%) oito e em três exemplares $(14,5 \%)$ cinco ramos (Figura 3).

FIGURA 3: Vista lateral direita da cavidade abdominal do javali, observa-se a artéria mesentérica cranial (Mcr) dando origem a artéria pancreaticoduodenal caudal (Pdc) e ramos pancreáticos $(\mathrm{Rp})$, artérias jejunais $(\mathrm{J})$ e artéria ileocecocolica (Icco).

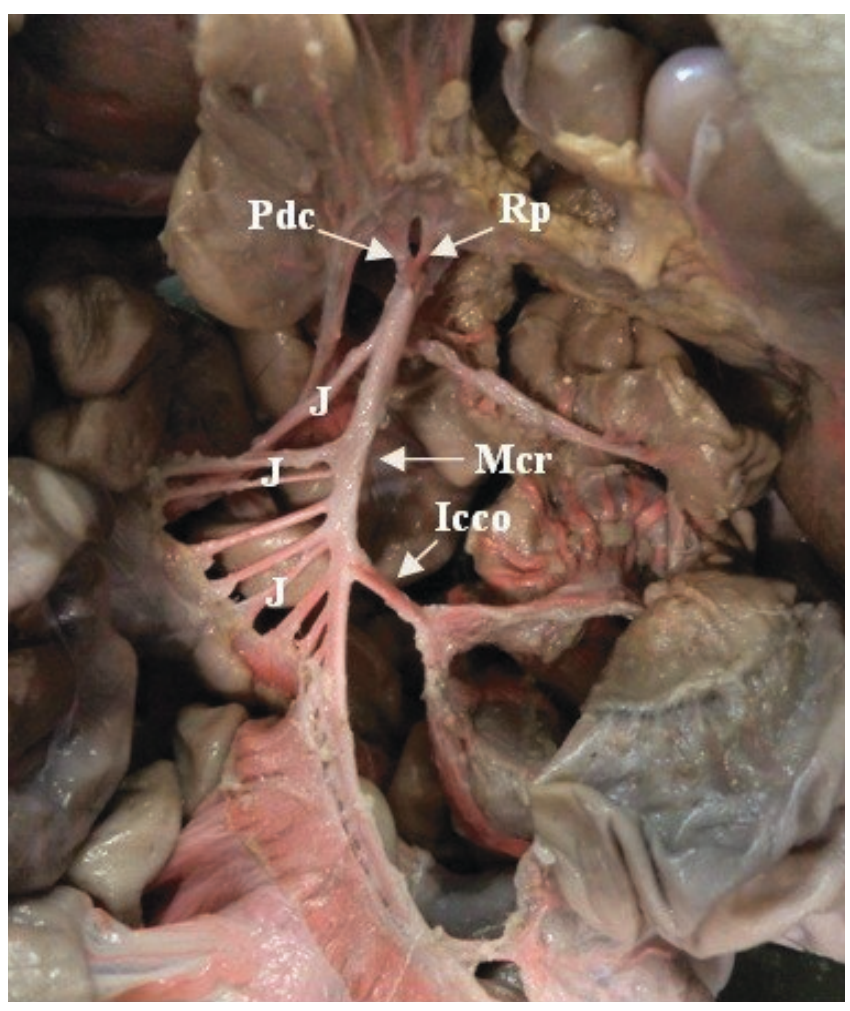

Artérias jejunais foram evidenciadas em número de cinco a dez, contadas até a origem da artéria ileocecocólica, sendo cinco em sete animais (33,3\%), seis em dois casos $(9,5 \%)$, sete em dois $(9,5 \%)$, oito em seis $(28,6 \%)$ e dez em quatro espécimes $(19,1 \%)$. Em todos os exemplares foram identificadas anastomoses destas entre si (Figura 2).

Artéria cólica média foi observada em todos os animais estudados, sendo que em duas ocasiões $(9,5 \%)$ não tinha origem em comum com a artéria cólica direita e não enviava ramos pancreáticos. Em oito casos $(38,2 \%)$ emitiram três ramos cólicos, em quatro ocasiões (19\%) enviava quatro, em seis oportunidades $(28,5 \%)$ cinco e em três exemplares, sete ramos (14,3\%). Em três animais $(14,3 \%)$ esta artéria não terminava em anastomose com a artéria cólica esquerda (Figura 2).
Artéria cólica direita estava presente em todos os espécimes estudados. Em três ocasiões (14,3\%), a artéria supracitada originava-se na face cranial da artéria mesentérica cranial. Fornecia ramos cólicos variando de cinco a nove, sendo em três animais (14,3\%) enviaram cinco ramos, em oito ocasiões $(38,2 \%)$ sete, em quatro casos $(19 \%)$, oito e em seis exemplares $(28,5 \%)$ enviavam nove cólicos (Figura 2).

Artéria ileocecocólica, encontrada em todos os animais, dava origem ao ramo cólico e a artéria ileocecal, a qual, em todos os casos analisados, dividia-se em artérias ileal e cecal. Em três ocasiões (14,3\%) ocorreu anastomose entre a artéria cecal e o ramo cólico e em um caso $(4,7 \%)$ anastomose entre as artérias cecal e cólica direita (Figura 3).

A artéria mesentérica caudal, presente em todos os espécimes, originou-se da face ventral do terço caudal da aorta abdominal, bifurcava-se em artérias cólica esquerda e retal cranial. Em seis ocasiões $(28,5 \%)$ ocorreu anastomose entre ambas. A artéria cólica esquerda emitiu de um a dois ramos, sendo que em 13 casos enviava um e em oito ocasiões, dois. A artéria retal cranial, por sua vez, em 12 exemplares emitia um ramo e em nove animais, dois.

\section{Discussão}

A artéria mesentéricas cranial surgiu da face ventral da aorta abdominal, de maneira isolada e imediatamente caudal à artéria celíaca, semelhante aos relatos de Getty (1981), Schwarze e Schröder (1991), Silva et al. (1997; 1998; 1999; 2000), Machado et al. (1999), Carvalho et al. (2002), Calábria et al. (2005) e Dyce et al. (2010). Entretanto, no que concerne aos seus ramos adrenais esquerdo e direito presentes em $42,8 \%$ e $71,4 \%$ dos exemplares estudados, respectivamente, condiz com relatos de Silva et al. (1999), o qual evidenciaram 20\%, e $86,7 \%$, respectivamente.

Quanto aos ramos pancreáticos presentes neste estudo em 71,4\% dos casos, podemos acrescentar que variam em número, o que reforçam as afirmações de Silva et al. (1999) e Calábria e Silva (2005), os quais citaram sua origem na artéria mesentérica cranial, 
contrapondo os dados de Nickel et al. (1981) que mencionaram a existência desses ramos, derivados desta, somente em ruminantes.

Os ramos originados de um tronco comum, destinados ao fígado e à parede da veia cava caudal, presentes em 4,7\% dos animais estudados, só foram mencionados por Silva et al. (1998, 1999), porém estes ainda citaram ramificações para adrenal esquerda oriunda deste tronco. No entanto, nenhum autor revisado relatou ramos destinados ao fígado e para a curvatura menor do estômago, cuja origem é um tronco comum, como ocorreu neste trabalho na frequência de $4,7 \%$.

No tocante à artéria pancreaticoduodenal caudal, sua apresentação nos javalis condiz com Schwarze e Schröder (1991), Silva et al. (1999) e König e Liebich (2004), no que diz respeito a sua origem, como tronco comum com artéria cólica direita, e distribuição, no pâncreas e duodeno. Já, Silva et al. (2000) encontraram tal artéria originando-se isoladamente da mesentérica cranial em todas as observações.

Foram evidenciadas de cinco a dez artérias jejunais, procedentes exclusivamente da artéria mesentérica cranial em javalis, o que corrobora com observações de Schawarze e Schröder (1991), que as evidenciaram nos suínos, estas em número de dez a doze, ao passo que Getty (1981) elucida quarenta e duas a setenta e nove de ramos diretos e indiretos. Todavia, este trabalho não se reportou ao critério de contagem das ramificações.

Complementando os aspectos relativos às artérias jejunais do javali, notamos que a primeira deu origem a ramos pancreáticos, aos quais também foram citados por Calábria e Silva (2005) em fetos de suínos da linhagem "Rezende".

A respeito das artérias cólicas direita e média, é perceptível uma diversidade de nomenclatura em relação aos tratadistas Sisson e Grossman (1975), Getty (1981), Nickel et al. (1981) e Schwarze e Schröder (1991) e os achados referentes a estas vasos confirmaram uma predominância na sua origem comum. Todavia, foi observado neste trabalho que em três casos $(14,3 \%)$ surgiram da artéria mesentérica cranial, fato em concordância com Machado et al. (1999) e Silva et al. (1997; 2000). Além desses achados, verificamos a emissão, por parte do tronco das artérias cólicas direita e média, de ramos pancreáticos, o que confere com dados relatados por Silva et al. (2000) e Calábria e Silva (2005).

Ademais, ocorreram anastomoses entre as artérias cólica direita e ramo cólico da ileocecocólica constatada por Silva et al. (1997; 2000). Não houve junções entre as artérias cólicas direita e media em três exemplares $(14,3 \%)$ deste estudo, fato que corrobora com observações dos autores supracitados.

A artéria ileocecocólica apresentou comportamento anatômico semelhante em todos os relatos revisados, dando origem à artéria ileocecal e ao ramo cólico, sendo que a primeira, posteriormente, se dividiu em artérias ileal e cecal. Ocorreram anastomoses entre os ramos das aterias ileal e cecal, de acordo com os citados por Getty (1981), Schwarze e Schröder (1991), Machado et al. (1999) e Silva et al. (1999). No entanto, nenhum autor consultado relatou anastomoses entre artéria cecal e ramo cólico e entre artérias cecal e cólica direita presentes neste estudo nas frequências de $14,3 \%$ e $4,7 \%$, respectivamente.

A artéria mesentérica caudal apresentou padrões de divisão e distribuição semelhantes àqueles relatados em suínos e queixada, todavia, vale ressaltar que em todos os casos as artérias cólica esquerda e retal cranial surgiram da artéria mesentérica caudal estando, em concordância com relatos de Sisson e Grossman (1975), Silva et al. (1997) e Carvalho et al. (2002). Getty (1981), Nickel et al. (1981), Schwarze e Schröder (1991) e Silva et al. (1997) acrescentaram que tal artéria surge na altura da quinta ou sexta vértebras lombares, porém, este detalhe não foi incorporado às nossas observações.

A artéria cólica esquerda, segundo Getty (1981), Nickel et al. (1981) e Schwarze e Schröder (1991) distribui-se no cólon descendente e anastomosa-se com as ramificações finais da artéria cólica média. Entretanto, não foi observada tal junção neste estudo.

De tudo que foi exposto, deve-se destacar que as informações da literatura, referentes à distribuição dos ramos oriundos das artérias mesentéricas cranial e caudal em suínos e queixada, mostraram-se semelhantes às encontradas neste trabalho. 
Segundo Machado et al. (1999) e Cubas et al (2007), os queixadas e catetos, pertencentes à família dos Tayassuidae, são parentes próximos na escala filogenética dos javalis e suínos domésticos, no entanto apresentam características morfológicas do aparelho digestório diferentes. A diferença está no estômago dos queixadas e catetos, o qual é composto e muito semelhante ao dos ruminantes, porém de menor eficiência.

Desta forma, no que diz respeito ao comportamento vascular das artérias que suprem os intestinos destas espécies, não era de se esperar diferenças significativas. Ao analisar as principais artérias oriundas das mesentéricas cranial e caudal, não foram observadas diferenças quanto à sua distribuição em queixadas, javalis e suínos domésticos.

Nas três espécies, as artérias mesentéricas cranial e caudal, pancreaticoduodenal caudal, jejunais, cólicas direita e média, e ileocecocólica apresentaram padrões vasculares semelhantes, visto que as diferenças quanto a emissão de ramos ou surgimento isolado ou em tronco comum não alteraram o suprimento sanguíneo.

\section{Agradecimentos}

Ao Conselho Nacional de Desenvolvimento e Cientifico e Tecnológico (CNPq), por ter financiado esta pesquisa e ao IBAMA e LAPAS por disponibilizarem as peças.

\section{Referências}

ANDERSSON, L.; ANDERSSON, K.; ANDERSSON, E. L.; ELLEGREN, H.; HALEY, C. S.; HANSSON, I.; JOHANSSON, M. M.; LUNDSTROM, K.; MARKLUND, L. Mapping qualititative trait loci for carcass and meat quality traits in a wild boar $\mathrm{x}$ large white intercross. Journal of Animal Science, Champaign, v. 76, p. 694-700, 1998.

CALÁBRIA, K. C.; SILVA, F. O. C. Origens e ramificações das artérias mesentéricas cranial e caudal em fetos de suínos da linhagem "Rezende". Veterinária Notícias, Uberlândia, v. 11, n. 1, p. 11-18, 2005.

CARVAlHO, D. M.; DRUMMOND, S. S.; SILVA, F. O. C.; MAZER, L. C. Origens e ramificações das artérias mesentéricas cranial e caudal de suínos da Raça Piau. Horizonte Científico, Uberlândia, v. 1, p. 1-11, 2002.
CUBAS, Z. S.; SILVA, J. C. R.; CATÃO-DIAS, J. L. Tratado de animais selvagens - medicina veterinária. São Paulo: Roca, 2007. $1354 \mathrm{p}$.

DYCE, K. M.; SACK, W. O.; WENSING, C. J. G. Tratado de anatomia veterinária. 4. ed. São Paulo: Elsevier, 2010. 840 p.

GETTY, R. Sisson/Grossman's anatomia dos animais domésticos. 5. ed. Rio de Janeiro: Interamericana, 1981. 2048 p.

INTERNATIONAL COMMITTEE ON VETERINARY GROSS ANATOMICAL NOMENCLATURE. Nomina Anatômica Veterinária. 15. ed. Columbia: Committee Hannover, 2005. 166 p. KÖNIG, H. E.; LIEBICH, H. Anatomia dos animais domésticos. São Paulo: Artmed, 2004. 400 p.

LUI, J. F.; MACUCO, V. S. O.; NETO, A. C., TOSTA, P. A.; MALHEIROS, E. B. Lipídeo, proteína e colesterol na carne de javalis (Sus scrofa scrofa) de diferentes grupos genéticos. Archivos de Zootecnia, Córdoba, v. 56, n. 216, p. 951-954, 2006.

MACHADO, G. V.; SANTOS, T. C.; PACHALY, J. R.; CAVALCANTE FILHO, M. F.; ANDRIOLI, L. G. Comportamento anatômico das artérias mesentéricas no queixada (Tayassu pecari, Link 1795). Arquivo Ciência Veterinária e Zoologia, Maringá, v. 2, n. 2, p. 119-124, 1999.

NICKEL, R.; SCHUMMER, A.; SEIFERLE, E. The circulatory system, the skin, and the cutaneous organs of the domestic mammals. In: IBID (Ed.). The anatomy of the domestic animals. v. 3. Berlin: Verlag Paul Parey, 1981. p. 169-176.

SCHWARZE, E.; SCHRÖDER, L. Compendio de anatomia veterinária. 9. ed. Zaragoza: Acribia, 1991. $350 \mathrm{p}$.

SEABRIGHT, M. The use of proteolytic enzymes for mapping of strutural rearrangement in the chromosome of man. Chromosoma, Berlin, v. 36, n. 2, p. 204-210, 1972.

SILVA, F. O. C.; MACHADO, G. V.; SEVERINO, R. S.; DRUMMOND, S. S.; SANTOS, A. L. Q.; MENEGATI, M. A. Aspectos anatômicos das artérias mesentéricas em suínos (Sus scrofa domestica Linnaeus, 1758) sem raça definida. Arquivo Ciência Veterinária e Zoologia, Maringá, v. 1, n. 2, p. 9-15, 1999. SILVA, F. O. C.; SEVERINO, R. S.; DRUMMOND, S. S.; SANTOS, A. L. Q.; BOMBONATO, P. P.; CALABRIA, K. C. Origens e ramificações das artérias mesentéricas cranial e caudal em fetos de suínos da raça Landrace. Veterinária Notícias, Uberlândia, v. 4, n. 1, p. 33-37, 1998.

SILVA, F. O. C.; SEVERINO, R. S.; DRUMMOND, S. S.; SANTOS, A. L. Q.; BOMBONATO, P. P.; CALÁBRIA, K. C. Origens e ramificações das artérias mesentéricas cranial e caudal em fetos de suínos da raça Pietrain. Brazilian Journal of Morphological Sciences, São Paulo, v. 17 (Suplemento), p. 129-132, 2000.

SILVA, F. O. C.; SEVERINO, R. S.; SANTOS, A. L. Q.; DRUMMOND, S. S.; BOMBONATO, P. P.; CALABRIA, K. C.; NETO, M. A. F. Origens e ramificações das artérias mesentéricas cranial e caudal em fetos de suínos da raça Large White. Veterinária Notícias, Uberlândia, v. 3, n. 1, p. 15-19, 1997.

SISSON, S.; GROSSMAN, J. D. Anatomia de los animales domésticos. 4. ed. Barcelona: Salvat, 1975. 952 p. 